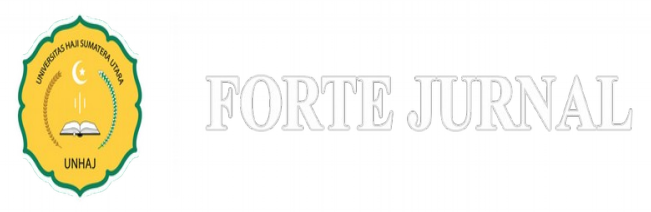

\title{
FORMULASI SEDIAAN SAMPO ANTI KETOMBE EKSTRAK DAUN BINAHONG (Anredera cordifilia (Tenore) Steen) TERHADAP AKTIVITAS JAMUR Candida albicans SECARA IN VITRO
}

\author{
Ovalina Sylvia Br. Ginting ${ }^{*}$, Robiatun Rambe ${ }^{2}$, Athaillah ${ }^{3}$, Pinte Mahara HS \\ ${ }^{1,2,3,4}$ Universitas Haji Sumatera Utara, Medan, Indonesia \\ *E-mail: ovalinasylviabr.ginting@gmail.com
}

\begin{abstract}
Abstrak
Rambut yang berketombe hingga kini masih menjadi salah satu penyebab berkurangnya kepercayaan diri yang dapat menghambat kenyamanan beraktivitas. Seiring berkembangnya pengobatan di Indonesia, perkembangannya kini mengarah kesistem pengobatan herbal, karena terbukti lebih aman dan tidak menimbulkan efek samping seperti obat-obat kimia. Salah satu faktor yang melatar belakangi penyebab ketombe adalah jamur Candida albicans.Ekstrak daun binahong (Anredera cordifilia (Tenore)Steen) merupakan bahan alam yang mengandung senyawa antijamur yaitu flavonoid dan saponin merupakan senyawa aktif yang dapat membunuh jamur candid albicans. Metode penelitian ini adalah eksperimental, yaitu Untuk mengetahui efektivitas sediaan sampo anti ketombe dari Ekstrak daun binahong (Anredera cordifilia (Tenore)Steen)terhadap aktivitas jamur Candida albicans penyebab ketombe dan mencari formula yang baik dan stabil secara fisika dan juga efektif digunakan sebagai anti ketombe.Metode penelitian ini menggunakan kontrol (-), kontrol (+), F1 (5\%), F2(10\%), dan F3 (15\%). Hasil penelitian sediaan sampo anti ketombe Ekstrak daun binahong (Anredera cordifilia (Tenore)Steen)dari ketiga variasi konsentrasi menunjukkan bahwa uji organoleptis sediaan sampo antiketombe Ekstrak daun binahong berwarna hijau tua dan hijau muda dan hijau kehitaman, berbentuk cairan kental, sedikit busa dan beraroma khasdaun binahong. Uji pH sampo yaitu 6,0, 6,0, dan 5,0. Uji tinggi busa yaitu $7,7 \mathrm{~cm}, 6,8 \mathrm{~cm}$, dan $6,5 \mathrm{~cm}$. Dan uji aktivitas sampo anti ketombe yaitu pada kontrol (+), kontrol (-), konsentrasi sampo anti ketombe ekstrak daun binahong $5 \%, 10 \%$ dan $15 \%$ yaitu $26,8 \mathrm{~mm}, 30,1 \mathrm{~mm}, 34,6 \mathrm{~mm}, 35,3 \mathrm{~mm}$, dan $35,2 \mathrm{~mm}$. Kesimpulan dari penelitian ini bahwa sediaan sampo anti ketombe ekstrak daun binahong dengan konsentrasi 5\%, 10\% dan 10\% telah memberikan daya hambat sangat kuat terhadap pertumbuhan jamur Candida albicans.Konsentrasi ekstrak daun binahongyang memiliki aktivitas penghambatan paling kuat terhadap pertumbuhan jamur Candida albicans adalah 35,3 mm dihasilkan oleh Formula II dengan konsentrasi 15\%.

Kata kunci : ekstrak daun binahong (Anredera cordifilia(Tenore)Steen), sediaan sampo antiketombe, aktivitas antijamur
\end{abstract}

\begin{abstract}
Dandruff hair is still one of the causes of reduced self-confidence which can hinder the comfort of doing activities. Along with the development of medicine in Indonesia, its development is now leading to the herbal medicine system, because it is proven to be safer and does not cause side
\end{abstract}


effects like chemical drugs. One of the factors behind the cause of dandruff is the fungus Candida albicans. Binahong leaf extract (Anredera cordifilia (Tenore) Steen) is a natural ingredient that contains antifungal compounds, namely flavonoids and saponins, which are active compounds that can kill candidal albicans fungi. This research method is experimental, namely to determine the effectiveness of anti-dandruff shampoo preparations from binahong leaf extract (Anredera cordifilia (Tenore) Steen) on the activity of the fungus Candida albicans that causes dandruff and to find a formula that is good and physically stable and also effective as an anti-dandruff. This research method uses control (-), control (+), F1 (5\%), F2 (10\%), and F3 (15\%).

The results of the research on anti-dandruff shampoo preparations Binahong leaf extract (Anredera cordifilia (Tenore) Steen) from the three concentration variations showed that the organoleptic test of the anti-dandruff shampoo preparation Binahong leaf extract was dark green and light green and blackish green, in the form of a thick liquid, little foam and has a distinctive aroma. binahong. The shampoo pH test was 6.0, 6.0, and 5.0. The foam height tests were $7.7 \mathrm{~cm}$, $6.8 \mathrm{~cm}$, and $6.5 \mathrm{~cm}$. And the anti-dandruff shampoo activity test is the control (+), control (-), the concentration of anti-dandruff shampoo with binahong leaf extract $5 \%, 10 \%$ and $15 \%$, namely $26.8 \mathrm{~mm}, 30.1 \mathrm{~mm}, 34.6 \mathrm{~mm}, 35,3 \mathrm{~mm}$, and $35.2 \mathrm{~mm}$. The conclusion of this study is that the binahong leaf extract anti-dandruff shampoo preparation with a concentration of $5 \%, 10 \%$ and $10 \%$ has a very strong inhibitory power against the growth of Candida albicans. The concentration of binahong leaf extract which has the strongest inhibitory activity against the growth of Candida albicans fungi is $35,3 \mathrm{~mm}$ is produced by Formula II with a concentration of $15 \%$.

Key words: binahong leaf extract (Anredera cordifilia (Tenore) Steen) anti-dandruff shampoo preparation, antifungal activity

\section{Pendahuluan}

Rambut yang menghiasi kepala manusia merupakan suatu kebutuhan estetika, sehingga banyak orang rela menghabiskan banyak waktu untuk merawat dan memperbaiki rambutnya. Gangguan kulit kepala sepert isensitif, berminyak dan berketombe, dapat mengganggu pertumbuhan rambut secara normal (Limbani et. al.,2009). Salah satu masalah yang dapat menyebabkan berkurangnya kepercayaan diri seseorang dalam beraktivitas ialah rambut berketombe (Mahataranti et.al., 2012).

Ketombe merupakan suatu keadaan pada kulit kepala, yang ditandai dengan terjadinya pengelupasan lapisan tanduk secara berlebihan dari kulit kepala membentuk sisik yang halus. Gejala umumnya ialah timbulnya sisik putih pada kulit kepala, gatal dan bias juga disertai kerontokan rambut. Berbagai kondisi memudahkan seseorang untuk terkena ketombe, antara lain faktor ginetik pertumbuhan kulit yang cepat, stres, kelelahan, dan kelainan neourologi (Sukandar et.al., 2006).

Penyebab ketombe dapat berupa sekresi kelenjar keringat yang berlebihan atau adanya peranan mikroorganisme di kulit kepala yang menghasilkan suatu metabolit yang dapat menginduksi terbentuknya ketombe di kulit kepala (Harahap, 1990). Indonesia merupakan Negara beriklimtropis yang memiliki kelembaban tinggi sehingga memungkinkan untuk tumbuhnya berbagai mikroorganisme dengan baik. Salah satu mikroorganisme yang dapat tumbuh dengan baik di Indonesia ialah jamur (Arifin, 2006). Menurut Ariyani et.al., (2009), salah satu jamur yang menimbulkan masalah ketombe pada rambut ialah jamur Candida albicans.

Pengobatan telah banyak dilakukan untuk mengatasi masalah ketombe yang dihadapi. Seiring berkembangnya pengobatan di Indonesia, perkembangannya kini mengarah ke system pengobatan herbal, karena terbukti lebih aman dan tidak menimbulkan efek samping seperti obat-obat kimia (Mahataranti et.al., 2012). Binahong (Anredera cordifilia (Tenore) Steen) adalah salah satu tanaman yang dapat dimanfaatkan 
untuk mengobati banyak penyakit diantaranya, untuk pengobatan luka bakar, penyakittifus, radangusus, sariawan, keputihan, pembengkakan hati, pembengkakan jantung, meningkatkan vitalitas dan daya tahan tubuh (Manoi, 2009). Binahong mengandung senyawa alkaloid, flavonoid, saponin, glikosida, teroid/terpenoida dan tanin (Katno et.al., 2006). Fungsi flavonoid adalah sebagai kerja antimikroba (Robinson, 1995). Saponin merupakan senyawa aktif yang dapat membunuh jamur Candida albicans (Robinson, 1995).

Berdasarkan penelitian yang telah dilakukan sebelumnya oleh Hermila (2011), yang berjudul Uji Aktivitas Anti fungi Ekstrak Etanol Daun Binahong (Anredera cordifilia (Tenore) Steen)terhadap Candida albicans beserta profil kromatografi lapis tipis, serta dalam jurnal (Sudiono, 2014), membuktikan bahwa ekstrak etanol 70\% dari daun binahong (Anredera cordifilia (Tenore) Steen) memiliki aktivitas yang baik terhadap daya hambat jamur Candida albicans. Berdasarkan latar belakang tersebut, maka penulis ingin melakukan penelitian terhadap aktivitas anti jamur Candida albicans yang merupakan salah satu jamur penyebab ketombe dengan menggunakan ekstrak etanol $70 \%$ daun binahong (Anredera cordifilia (Tenore) Steen) yang di formulasikan dalam bentuk sediaan sampo agar memudahkan dalam pemanfaatannya sebagai anti ketombe.

Metode yang digunakan untuk pengujian anti jamu rsecara invitro adalah metode difusi sumuran serta menggunakan PDA sebagai media pertumbuhan jamur. Alasan penggunaan metode sumuran karena lebih mudah dalam mengukur luas zona hambat yang terbentuk sebab isolat memberikan aktivitas daya hambat tidak hanya dipermukaan agar, tetapi juga sampai kedasar media agar (Saputro, 2006).

Berdasarkan uraian masalah diatas maka permasalahan yang akan di teliti adalah:

1. Apakah golongan senyawa kimia yang terkandung dalam ekstrak daun binahong (Anredera cordifilia (Tenore) Steen) diperoleh dari kota Takengon Kabupaten Aceh Tengah Provinsi Nanggroe Aceh Darusalam?

2. Apakah ekstrak daun binahong (Anredera cordifilia (Tenore) Steen) mempunyai aktivitas anti jamur terhadap Candida albicans?

3. Apakah sediaan sampo dari ekstrak daun binahong (Anredera cordifilia (Tenore) Steen) dapat menghamba tpertumbuhan jamur penyebab ketombe?

Berdasarkan rumusan masalah diatas maka tujuan yang ingin dicapai dalam penelitian ini yaitu:

1. Untuk mengetahui golongan senyawa kimia yang terkandung dalam ekstrak daun binahong (Anredera cordifilia (Tenore) Steen) diperoleh dari kota Takengon Kabupaten Aceh Tengah Provinsi Nanggroe Aceh Darusalam.

2. Untuk mengetahui efektivitas sediaan sampo anti ketombe dari ekstrak daun binahong (Anredera cordifilia (Tenore) Steen) terhadap aktivitas jamur Candida albicans penyebab ketombe dan mencari formula yang baik dan stabil secara fisika dan juga efektif digunakan sebagai anti ketombe.

3. Untuk mengetahui konsentrasi sampo ekstrak daun binahong (Anredera cordifilia (Tenore) Steen) yang memiliki aktivitas penghambat paling kuat terhadap pertumbuhan jamur candida albicans. 


\section{Metode Penelitian Alat dan Bahan}

Alat yang digunakan pada penelitian ini adalah alat-alat gelas standar laboratorium, aluminium foil, ayakan, batang pengaduk, blender (MIYAKO), bunsen, cawan porselin, cawan petri (PYREX), cawan kurs, corong gelas (PYREX), Erlenmeyer (PYREX), Beaker gelas (PYREX), Tabung reaksi (PYREX), hot plat (IKA), kawat ose, Kawat kasa, klem dan statif, lampu bunsen, autoklaf (BONE), laminar air flow (LOKAL), mikropipet, oven (MEMMERT), penggaris berskala, Universal pH Paper, pencadang logam, spatula, timbangan analitik (OHOUS), wadah sampo.

Bahan yang digunakan pada penelitiaan ini ialah daun ekstrak binahong (Anredera cordifilia (Tenore) Steenis), jamur Candida albicancs, etanol 70\%, natrium lauril sulfat, cocamide, DEA, Na-CMC, menthol, asam sitrat, metil paraben, aquadest, potato dextrose agar (PDA), sampo ketombe ketokonazol 2\%, $\mathrm{NaCl} 0,9 \%$ dan larutan standar Mc. Farland.

\section{Prosedur Penelitian \\ Karakterisasi simplisia \\ Uji kadar air}

Penetapan kadar air dilakukan secara pemanasan. Serbuk ditimbang sebanyak 2 gram dalam cawan yang telah diketahui beratnya. Kemudian keringkan dalam oven pada suhu $100-105^{\circ} \mathrm{C}$ selama 3-5 jam. Kemudian dinginkan dan ditimbang. Panaskan lagi dioven selama 30 menit, dinginkan dan ditimbang. Pengurangan berat merupakan banyaknya air dalam bahan (Maharani,2013).

\section{Uji kadar abu total}

Sebanyak 2 gram ekstrak kering di timbang, dimasukkan kedalam krus porselin yang telah dipijarkan dan ditara, diratakan.Pijarkan pelahan-lahan hingga arang habis, didinginkan dan ditimbang. Jika dengan cara ini arang tidak dapat dihilangkan, tambahkan air panas, saring melalui kertas saring bebas abu, pijarkan sisa dan kertas saring dalam krus yang sama. Masukkan filtrat kedalam krus, uapkan setelah itu pijarkan hingga bobot tetap, timbang. Hitung kadar abu terhadap bahan yang telah dikeringkan diudara (Depkes RI, 2000).

\section{Uji kadar abu yang tidak larut asam}

Abu yang diperoleh pada penetapan kadar abu, dididihkan selama $25 \mathrm{ml}$ asam klorida encer selama 5 menit, kumpulkan bagian yang tidak larut dalam asam. Saring melalui kurs kaca masir atau kertas saring bebas abu, cuci dengan air panas, pijarkan hingga bobot tetap, lalu ditimbang. Hitung kadar abu yang tidak larut dalam asam terhadap bahan yang telah dikeringkan diudara (Depkes RI, 2000).

\section{Penetapan kadar sari yang larut dalam air}

Sebanyak $5 \mathrm{~g}$ serbuk simplisia, dimaserasi selama 24 jam dalam $100 \mathrm{ml}$ airkloroform (2,5 ml kloroform dalam air suling sampai 1 liter $)$ dalam labu bersumbat sambil dikocok sesekali selama 6 jam pertama, kemudian dibiarkan selama 18 jam, lalu disaring. Sejumlah $20 \mathrm{ml}$ filtrat pertama diuapkan sampai kering dalam cawan penguap yang berdasar rata yang telah ditara dan sisa dipanaskan pada suhu $105^{\circ} \mathrm{C}$ sampai diperoleh bobot tetap. Kadar sari yang larut dalam air dihitung terhadap bahan yang telah dikeringkan (Ditjen POM, 1995).

\section{Penetapan kadar sari yang larut dalam etanol}

Sebanyak $5 \mathrm{~g}$ serbuk simplisia dimaser asi selama 24 jam dalam $100 \mathrm{ml}$ etanol 96\% dalam labu bersumbat sambil dikocok sesekali selama 6 jam pertama, kemudian 
dibiarkan selama 18 jam. Larutan tersebut disaring cepat untuk menghindari penguapan etanol.Sejumlah $20 \mathrm{ml}$ filtrat diuapkan sampai kering dalam cawan penguap yang berdasar rata yang telah dipanaskan dan ditara. Sisa dipanaskan pada suhu $105^{\circ} \mathrm{C}$ sampai diperoleh bobot tetap.Kadar sari yang larut dalam etanol 96\% dihitung terhadap bahan yang telah dikeringkan (Ditjen POM, 1995).

\section{Pembuatan Ekstrak Etanol Daun Binahong}

Sebanyak $200 \mathrm{~g}$ serbuk simplisia daun binahong (masing-masing daun binahong) dimasukkan ke dalam wadah gelas berwarna gelap lalu dimaserasi dengan 7,5 bagian pelarut etanol $70 \%$ selama 5 hari terlindung dari cahaya matahari sambil sering diaduk, setelah 5 hari hasil maserasi disaring dan diperas dengan kertas saring lalu ampasnya ditambahkan cairan penyari secukupnya sehingga diperoleh seluruh maserat sebanyak 2 liter. Kemudian maserat didiamkan selama 2 hari dan dienap tuangkan. Maserat diuapkan dengan bantuan alat penguap rotari evaporator pada temperatur tidak lebih dari $70{ }^{\circ} \mathrm{C}$ dan di freeze dryer sampai diperoleh ekstrak kental (Ginting, 2017).

Formulasi dasar pembuatan sampo dalam penelitian ini dapat dilihat pada tabel 1 di bawah ini.

Tabel 1. Formula standar

\begin{tabular}{lc}
\hline \multicolumn{1}{c}{ Bahan } & Standar \\
\hline Natrium Lauril Sulfat & $5 \%(\mathrm{~b} / \mathrm{v})$ \\
Cocamide DEA & $2 \%(\mathrm{~b} / \mathrm{v})$ \\
Na-CMC & $1.5 \%(\mathrm{~b} / \mathrm{v})$ \\
Asam Sitrat & $1 \%(\mathrm{~b} / \mathrm{v})$ \\
Menthol & $0.12 \%(\mathrm{~b} / \mathrm{v})$ \\
Metil Paraben & $0,1 \%(\mathrm{~b} / \mathrm{v})$ \\
Aquadest & Ad $50 \mathrm{Ml}$ \\
\hline
\end{tabular}

Sumber : Maesaroh, 2016

Tabel 2. Formula sediaan sampo antiketombe dari ekstrak daun binahong (anredera cordifilia (Tenore) Steen)

\begin{tabular}{|c|c|c|c|c|}
\hline \multirow[t]{2}{*}{ Bahan } & \multicolumn{4}{|c|}{$\begin{array}{l}\text { Formulasi sampo antiketombe dengan berbagai konsentrasifraksi } \\
\text { aquadest daun binahong }\end{array}$} \\
\hline & $\mathrm{F} 0$ & $\mathrm{~F} 1$ & $\mathrm{~F} 2$ & $\mathrm{~F} 3$ \\
\hline $\begin{array}{l}\text { Fraksi aquades daun } \\
\text { binahong }\end{array}$ & 0 & $10 \%$ & $20 \%$ & $30 \%$ \\
\hline Natrium Lauril Sulfat & $5 \%$ & $5 \%$ & $5 \%$ & $5 \%$ \\
\hline Cocamide DEA & $2 \%$ & $2 \%$ & $2 \%$ & $2 \%$ \\
\hline $\mathrm{Na}-\mathrm{CMC}$ & $1.5 \%$ & $1.5 \%$ & $1.5 \%$ & $1.5 \%$ \\
\hline Asam Sitrat & $1 \%$ & $1 \%$ & $1 \%$ & $1 \%$ \\
\hline Menthol & $0,12 \%$ & $0,12 \%$ & $0,12 \%$ & $0.12 \%$ \\
\hline Metil Paraben & $0,1 \%$ & $0,1 \%$ & $0,1 \%$ & $0.1 \%$ \\
\hline Aquadest & $50 \mathrm{ml}$ & $50 \mathrm{ml}$ & $50 \mathrm{ml}$ & $50 \mathrm{ml}$ \\
\hline
\end{tabular}

\section{Prosedur Pembuatan Sampo}

Setelah didapatkan konsentrasi Na-CMC yang optimal, dilakukkan formulasi sampo dengan 3 formula yang berbeda yaitu F1 5\%, F2 10\%, F3 15\%.

Cara pembuatannya adalah sebagai berikut:

1. Disiapkan alat dan bahan

2. Masukkan Na-CMC yang telah ditimbang dalam air panas. Biarkan beberapa menit sampai mengembang dan diaduk perlahan (massa 1) 
3. Air yang dipanaskan pada suhu $60-70^{\circ} \mathrm{C}$ sebanyak $20 \mathrm{ml}$ dimasukkan kedalam beaker glass, kemudian tambahkan Sodium Lauryl Sulfat, aduk sampai larut (massa 2)

4. Larukan menthol dengan etanol $70 \%$ secukupnya, aduk sampai larut kemudian tambahkan metil paraben aduk sampai homogen

5. Larutan Sodium Lauryl Sulfat (massa 2) dimasukkan sedikit demi sedikit kedalam (massa 1) sambil diaduk perlahan hingga homogen

6. Tambahkan Cocamide DEA sedikit demi sedikit, aduk homogen

7. Masukkan larutan campuran (3) kedalam campuran (4), aduk perlahan sampai homogen

8. Masukkan rendaman ekstrak daun binahong, dan aduk homogen

9. Masukkan kedalam botol $50 \mathrm{ml}$ (maesaroh, imas, 2016). 


\section{Hasil Penelitian}

ekstrak etanol daun binahong diperoleh dari serbuk simplisia ekstrak daun binahong 230 gram yang diekstraki dengan metode maserasi sebanyak tiga kali replikasi dan menggunakan pelarut etanol dengan total pelarut sebanyak $1500 \mathrm{ml}$ kemudian disaring sehingga diperoleh maserat jernih. Maserat etanol yang terkumpul diuapkan dengan penangas air sampai diperoleh ekstrak kental daun binahong sebanyak 30 gram. Hasil yang diperoleh kemudian dihitung dan didapatkan rendemen ekstrak etanol daun binahong sebesar $15 \%$.

Tabel 3. Hasil uji parameter non spesifik simplisia daun binahong (Anredera cordifilia (Tenore) Steen).

\begin{tabular}{llcl}
\hline & & & Daun binahong \\
& Ko & Karakteristik serbuk simplisia & Ketentuan (\%) \\
\hline 1 & Kadar air & $9.8 \%$ & Tidak lebih dari $10 \%$ \\
2 & Kadar sari yang larut dalam air & $5,6 \%$ & Tidak lebih dari $16,3 \%$ \\
3 & Kadar sari yang larut dalam etanol & $12,6 \%$ & Tidak lebih dari $1,9 \%$ \\
4 & Kadar abu total & $9.3 \%$ & Tidak kurang dari $13,5 \%$ \\
5 & Kadar abu tidak larut asam & $0,69 \%$. & Tidak kurang dari $19,6 \%$ \\
\hline
\end{tabular}

Penetapan kadar air dilakukan untuk mengetahui besarnya kandungan air yang terdapat dalam serbuk simplisia. Menurut Materia Medika indonesia (1995), syarat kadar air yang baik tidak lebih dari 10\%. Kadar air yang diperoleh adalah $10 \%$ dimana hasil ini memenuhi persyaratan. 
Tabel 4. Hasil pengujian skrining fitokimia

\begin{tabular}{llll} 
NO. & \multicolumn{1}{c}{ Parameter } & Hasil & \multicolumn{1}{c}{$\begin{array}{c}\text { Daun Binahong } \\
\text { Keterangan }\end{array}$} \\
\hline 1. & Flavonoid & + & $\begin{array}{l}\text { Lapisan amil alkohol berwarna kuning } \\
\text { Busa stabil }\end{array}$ \\
2. & Saponin & + & Terbentuknya warna hijau \\
3. & Tanin & + & Terbentuknya endapan merah bata \\
4. & Alkaloid & + & Terbentuknya cincin berwarna ungupada \\
5. & Glikosida & + & $\begin{array}{l}\text { batas cakram } \\
\text { 6erbentuknya warna hijau (steroid) }\end{array}$ \\
6. & Steroid/Terpenoida & + &
\end{tabular}

Keterangan:

$(+)$ positif : mengandung golongan senyawa

(-) negatif : tidak mengandung golongan senyawa

\section{Uji organoleptis}

Tabel 5. Hasil pengamatan organoleptis

\begin{tabular}{lllll}
\hline No & Sediaan & Bentuk & \multicolumn{1}{c}{ Warna } & \multicolumn{1}{c}{ Bau } \\
\hline 1 & Fo rmula 0 & Cairan kental & Putih & Khas mentol \\
2 & Formula 1 & Cairan kental & Hijau muda & Khas daun binahong \\
3 & Formula 2 & Cairan kental & Hija tua & Khas daun binahong \\
4 & Formula 3 & Cairan kental & Hijau tua & Khas daun binahong \\
\hline
\end{tabular}

\section{Pengamatan Uji pH}

Tabel 6. Hasil pengamatan uji pH

\begin{tabular}{lll}
\hline & Formula & Hasil uji pH \\
\hline Formula 0 & & 5,0 \\
Formula 1 & 6,0 & \\
Formula 2 & 6,0 & \\
Formula 3 & 6,0 & \\
\hline
\end{tabular}

\section{Pengamatan Uji Tinggi Busa}

Tabel 7 . Hasil pengamatan uji tinggi busa

\begin{tabular}{ll}
\hline Formula & Hasil uji tinggi busa \\
\hline Formula 0 & 6,3 \\
Formula 1 & 7.1 \\
Formula 2 & 7.9 \\
Formula 3 & 8,5 \\
\hline
\end{tabular}


Hasil Uji Aktivitas Sampo Antiketombe

Tabel 8. Hasil Uji Aktivitas Sampo Antiketombe

\begin{tabular}{|c|c|c|c|c|c|}
\hline \multicolumn{3}{|c|}{ diameter zona hambat $(\mathrm{mm})$} & \multirow{2}{*}{\multicolumn{3}{|c|}{ Formulasi sediaan sampo antiketombe }} \\
\hline \multirow[t]{2}{*}{ NO } & \multirow{2}{*}{\multicolumn{2}{|c|}{$\begin{array}{c}\text { Larutan kontrol } \\
+\end{array}$}} & & & \\
\hline & & & $\mathrm{F} 1$ & $F 2$ & F3 \\
\hline 1 & 29,6 & 28,8 & 20,2 & 25,2 & 24,0 \\
\hline 2 & 30,8 & 30,9 & 34,3 & 30,3 & 31,0 \\
\hline 3 & 30,9 & 30,7 & 33,3 & 35,4 & 35,4 \\
\hline Rata-rata & 30,4 & 30,1 & 29,2 & 30.3 & 30,1 \\
\hline
\end{tabular}

\section{Pembahasan}

Pada penelitian ini dipilih sediaan sampo karena masalah pada rambut berketombe. ketombe pada rambut adalah masalah umum penduduk dunia. Setiap bulan sel kulit kepala yang mati akan digantikan oleh sel-sel yang baru secara alami. Sel-sel kulit mati tersebut merupakan penyebab ketombe (Said H., 2009).

Sampo adalah sediaan kosmetik pembersih rambut dan kulit kepala yang digunakan untuk membersihkan rambut dan kulit kepala dari segala macam kotoran, baik yang berupa minyak, debu, sel-sel yang sudah mati dan sebagainya secara baik dan aman (Ratno et.al., 2009).

Metode penentuan kadar sari larut air maupun larut etanol bertujuan untuk menentukan jumlah senyawa aktif yang terekstrasi dalam pelarut sejumlah serbuk simplisia. Hasil menunjukkan kadar kadar sari larut air dari serbuk simplisia daun binahong memiliki nilai 5,6\%, sedangkan kadar sari larut etanol sebesar 12,6\%. Hal ini menunjukkan bahwa sejumlah senyawa polar yang terlarut dalam air lebih kecil dari pada jumlah senyawa kurang dari polar (semi polar maupun non polar) yang terlarut dalam etanol, selain itu dapat merupakan indikator banyaknya zat berkhasiat yang dapat tersari oleh pelarut air dan etanol.

Penetapan kadar abu total bertujuan untuk mengetahui kadar senyawa-senyawa organik seperti oksida logam $\mathrm{Mg}, \mathrm{Ca}, \mathrm{Pb}$, dan $\mathrm{Zn}$ penetapan kadar abu tida $\mathrm{k}$ larut dalam asam dilakukan untuk mengetahui kadar senyawa yang tidak larut dalam asam. Hasil yang didapat untuk kadar abu total adalah kadar abu tidak larut dalam asam adalah sebesar $9,3 \%$ dan $0,69 \%$.

Pengujin skrining fitokimia pada ekstrak daun binahong dilakukan untuk mengetahui golongan metabolit sekunder yang terdapat pada ekstrak.Hasil penapisa fitokimia yang dilakukan pada ekstrak daun binahong didentifikasi adanya tanin, flavonoid, dan saponin. Efek antibakteri terhadap ekstrak adalah karena adanya senyawa-senyawa tersebut, senyawa aktif berupa, tanin, flavonoid dan saponin adalah senyawa yang berperan utama dalam membunuh bakteri patogen. Daun binahong mengandung berbagai macam senyawa kimia yang berfungsi sebagai antibakteri yaitu flavonoid, saponin, tanin, Alkaloid, Glikosida, Steroid/Terpenoida.

Hasil pembuatan sampo antiketombe ekstrak binahong pada F0, F1, F2, dan F3 didapatkan sampo anti ketombe dengan tekstur cairan kental yang sedikit busa sehingga mudah dituang. Pada proses pembuatan sampo perlu diperhatikan kecepatan menggerus sehingga sediaan menjadi homogen. Pencampuran natrium lauril sulfat dalam air dengan penangas air dilakukan perlahan-lahan agar terlarut, penggerusan selama proses pencampuran bahan-bahan lain sebisa mungkin dilakukan dengan perlahan dan konstan agar tidak terbentuk busa yang berlebihan pada sediaan sampo. 
Setelah sediaan dibuat maka dilakukan evaluasi organoleptis meliputi pengamatan dari bentuk, warna, dan aroma sediaan. Hasil pengamatan organoleptis sampo antiketombe ekstrak binahong dengan berbagai konsentrasi menunjukkan bentuk sampo cairan kental dan sedikit busa, warna F0 menunjukan warna putih, F1 berwarna hijau muda, F2 hijau tua, dan F3 hijau tua. dengan bau mentol dan khas daun binahong pada semua formulasi. Semakin tinggi konsentrasi ekstrak binahong pada sediaan sampo maka semakin pekat warna hijau tua pada sediaan sampo.

Pengukuran $\mathrm{pH}$ sediaan sampo anti ketombe dilakukkan dengan menggunakan $\mathrm{pH}$ meter. pH sampo menurut standar SNI No. 06- 2692-1992 yaitu berkisar 5,0-9,0 dimana angka tersebut merupakan $\mathrm{pH}$ normal kulit agar sampo yang dibuat tidak mengiritasi kulit kepala. $\mathrm{pH}$ sampo terlalu asam maupun terlalu basa akan mengiritasi kulit kepala. $\mathrm{pH}$ merupakan parameter yang dapat mempengaruhi daya absorpsi sediaan kedalam kulit. Pemeriksaan $\mathrm{pH}$ bertujuan untuk melihat derajat keasaman dari sediaan sampo. Cara pengukuran $\mathrm{pH}$ menggunakan Universal $\mathrm{pH}$ Paper. Sampel dibuat dalam konsentrasi 1\% yaitu ditimbang $1 \mathrm{~g}$ sediaan dan dilarutkan dalam $10 \mathrm{ml}$ aquades. Setelah itu dicelupkan dalam larutan tersebut (Mita Sr et.al., 2009).

Berdasarkan hasil pengukuran $\mathrm{pH}$ menggunakan Universal $\mathrm{pH}$ Paper terhadap sediaan sampo antiketombe ekstrak binahong didapatkan hasil Nilai pH F0 5.0, F1 6.0, F2 6.0 dan F3 6,0. Dari hasil penelitian menunjukan bahwa semakin besar konsentrasi ekstrak daun binahong yang digunakan, maka semakin besar nilai $\mathrm{pH}$ sediaan sampo, Nilai $\mathrm{pH}$ formulasi sampo antiketombe yang memenuhi persyaratan SNI karena masih berada pada rentang pH sesuai persyaratan (Departemen Kesehatan RI., 1985).

Pada pemeriksaan tinggi busa didapatkan hasil yang menunjukkan kemampuan surfaktan membentuk busa. Tinggi busa yang didapat dari keempat formulasi sampo berkisar 6,3-8.5 cm. dimana angka tersebut memenuhi persyaratan tinggi busa menurut (walkinson, 1982) yaitu 1,3- $22 \mathrm{~cm}$. Dari hasil pengukuran tingi busa menunjukkan bahwa adanya peningkatan daya pembusa. Dilihat dari hasil pengujian tinggi busa F1, F2, dan $\mathrm{F} 3$ adalah $7,1 \mathrm{~cm}, 7,9 \mathrm{~cm}$, dan $8,5 \mathrm{~cm}$ sementara untuk tinggi busa kontrol tanpa penambahan zat aktif yaitu $6,3 \mathrm{~cm}$. Peningkatan tinggi busa pada F1, F2, dan F3 diakibatkan pengaruh zat aktif ekstrak binahong yang diketahui memiliki kandungan senyawa saponin. Menurut harbone (1996) saponin dapat membentuk busa. Sementara F0 yang hanya mengandung basis sampo mengalami penurunan tinggi busa dikarenakan basis sampo tersebut tanpa penambahan ekstrak binahong dimana ekstrak binahong mengandung saponin yang dapat membentuk busa(Anita lukman, wahyuni A, 2007).

Sediaan sampo anti ketombe dengan berbagai konsentrasi yang dibuat diuji aktivitasnya terhadap pertumbuhan jamur Candida albicans dan menggunakan PDA sebagai media pertumbuhan. Jamur yang digunakan berasal dari Laboratorium Mikrobiologi Fakultas Farmasi Universitas Sumatera Utara Medan. Media dipilih karena dapat mendukung pertumbuhan jamur Candida albicans yang memiliki karakteristik dapat tumbuh cepat pada kondisi asam dibandingkan dengan $\mathrm{pH}$ normal. Selain itu jamur dapat tumbuh baik pada media PDA karena mengandung sumber karbohidrat (Sitompul mb.,2016).

Pengujian antijamur dilakukan dengan sediaan sampo antiketombe ekstrak binahong konsentrasi F1 (10\%), F2(20\%), dan F3(30\%) dan sebagai pembandingnya kontrol negatif yaitu basis sampo tanpa ekstrak binahong dan kontrol positif yaitu Sediaan sampo Ketokonazol 2\% antiketombe. Pada masing-masing perlakuan menunjukkan adanya zona hambat yang ditandai pada daerah bening yang terbentuk disekitar sumuran.

Diantara ketiga formulasi sampo antiketombe ekstrak binahong, zona hambat terbesar terdapat pada sampo yang mengandung ekstrak binahong (F2)20\% yaitu 30,3 mm, sedangkan zona hambat terendah terdapat pada sampo yang mengandung ekstrak 
binahong (F1)10\% yaitu 29,2 $\mathrm{mm}$. Dan diameter zona hambat pada sampo yang mengandung ekstrak binahong (F3)30\% yaitu 30,1 mm. Pada kontrol positif yang menggunakan ketokonazol $2 \%$ anti ketombe yang terbentuk diameter zona hambat sebesar 30,4 $\mathrm{mm}$. Dari hasil pengujian terlihat bahwa semakin tinggi konsentrasi ekstrak binahong didalam formulasi sediaan sampo maka semakin besar aktivitas antijamur yang dihasilkan.

Kontrol negatif yang digunakan adalah basis sampo tanpa penambahan, hasil dari pengukuran antijamur kontrol negatif adalah $30,1 \mathrm{~mm}$, tidak begitu berbeda jauh dengan hasil pengukuran pada FI yaitu $29,2 \mathrm{~mm}$, hal ini menunjukkan bahwa kontrol negatif memberikan efek pada pengujian aktivitas antijamur sehingga menghasilkan zona hambat terhadap pertumbuhan jamur Candida albicans. Hasil tersebut menunjukkan bahwa ada bahan didalam formulasi sampo yang berfungsi sebagai antijamur.

\section{Kesimpulan}

1. Golongan senyawa kimia yang terkandung dalam serbuk simplisia binahong meliputi skrining flavonoid ada lapisan amil alkohol berwarna kuning, saponinterkandung busa stabil, tanin terbentuknya warna hijau, Alkaloid terbentuknya endapan merah bata, Glikosida terbentuknya cincin berwarna unggu, dan Steroid/Terpenoida terbentuknya endapan hijau. Dihasilkan positif.

2. Ekstrak daun binahong (Anredera cordifilia (Tenore) Steen). Memiliki aktivitas antifungi terhadap Candida albicans setelah diformulasi dalam sediaan sampo dengan diameter hambat 29,2 mm yang dihasilkan oleh FI konsentrasi 10\%, 30,3 mm dihasilkan oleh FII dengan konsentrasi 20\%, 30,1 mm dihasilkan oleh FIII dengan konsentrasi 30\%. Berdasarkan hasil evaluasi sediaan sampo antiketombe Ekstrak daun binahong seluruh formula memiliki sifat fisik yang baik dan stabil selama penyimpanan.

3. Konsentrasi sediaan sampo antiketombe Ekstrak daun binahong yang memiliki aktivitas penghambatan paling kuat terhadap pertumbuhan jamur Candida albicansadalah 35,6 mm dihasilkan oleh Formula II dengan konsentrasi 10\%.

\section{Referensi}

Anita Lukman, Wahyuni A, 2017. Formulasi Sampo Perasan Jeruk Purut (Citrus Hystrix D.C) Dan Uji Aktivitas Anti Ketombe Terhadap Jamur Penyebab Ketombe (Pityrosporum Ovale) Secara In Vitro. J Penelit Farm Indones. $7(1): 36-40$.

Arifin, Z. 2006. Kajian Mikoriza Vesikula Arbuskula (MVA) dalam Menekan Perkembangan Penyakit Bercak Ungu (Alternaria porri) pada Bawang Putih. [Disertasi]. Fakultas Ilmu Pertanian Universitas Gadjah Mada, Yogyakarta.

Ariyani., S.D. Dewi.,dan R. Haribi. 2009. "Daya Hambat Sampo Anti Ketombe Terhadap Pertumbuhan C. Albicans Penyebab Ketombe". Jurnal Kesehatan. 2(2): 7-10.

Departemen Kesehatan Republik Indonesia., 2000. Farmakope indonesia. Edisi IV Jakarta : Depkes RI.

Departemen Kesehatan RepublikIndonesia, 1985. Formularium Kosmetika Indonesia.

Ditjen POM. (1995). Farmakope indonesia Edisi IV. Jakarta: Departemen Kesehatan RI. Hal. 1112-1116. 
Ginting,O.S. 2017. Perbandingan Aktivitas Antibakteri Ekstrak Etanol Biji Pepaya (Carica papaya L.) dari dua Varietas Terhadap bakteri Escherichia coli. Jurnal, vol 1 no 2.

Harahap, M. 1990. Penyakit Kulit. Gramedia, Jakarta.Arifin, Z. 2006. "Kajian Mikoriza Vesikula Arbuskula (MVA) dalam Menekan Perkembangan Penyakit Bercak Ungu (Alternariaporri) pada Bawang Putih".[Disertasi].Fakultas Ilmu Pertanian Universitas Gadjah Mada, Yogyakarta.

Hermila, 2011."Uji Aktivitas Anti fungi Ekstrak Etanol Daun Binahong (Anredera cordifolia (Tenore) Steen.) terhadap Candida albicans Beserta Profil Kromatografi lapis Tipis", Skripsi, Fakultas Farmasi Universitas Ahmad Dahlan, Yogyakarta.

Katno, Dyah S., Rohmat M. danHarto W., 2006, "InventarisTanamanObat Indonesia", edisi VI, Departemen Kesehatan Badan Penelitian dan Pengembangan Kesehatan Balai Penelitian Tanaman Obat, Jakarta, Hal : 16-17.

Limbani, M., M.R. Dabhi., M.K. Raval., and N.R. Sheth. 2009. "Clear Shampoo: an Important Formulation Aspect with Consideration of the Toxicity of Commonly Used Shampoo Ingredients". Saurashtra University, India

Mahataranti, N., I.Y. Astuti., dan B. Asrining dhiani. 2012. "Formulasi Shampo Anti ketombe Ekstrak Etanol Seledri (Apium Graveolens L.) dan Aktivitasnya Terhadap Jamur Pityrosporumovale". Jurnal Pharmacy. 9(2): 128-138.

Maharani, 2013. Organizational citizenship behavior role in mediating the effect of transformational leadership, job satisfaction on employee performance: studiesin PT bank syariah mandiri malang East Java. Internasional Journal of business and Management; Vol. 8, No. 17; 2013.

Manoi, 2009, "BinahongSebagaiObat", WARTA Penelitian dan Pengembangan Tanaman Industri Volume 15 No.(1): Pusat Penelitian dan Perkembangan Perkebunan, Yogyakarta, diakses 14 Desember 2010.

Maesaroh, 2016. Formulasi Sediaan Shampoo Jelly Antiketombe dari Ekstrak Kangkung (Ipomoea Aquatica Forssk). Jurnal Ilmiah KORPRI Kopertis Wilayah IV; Vol. 1 (1): Hal 81-86;

Mita Sr, Rusmiati D, Kusuma Saf, 2009. Pengembangan Ekstrak Etanol Kubis (Brassica Oleracea Var. Capitata L.) Asal Kabupaten Bandung Barat Dalam Bentuk Sampo Antiketombe Terhadap Jamur Malassezia Furfur. Lap Akhir Penelit Peneliti Muda Tidak Diterbitkan Bandung Univ Padjadjaran.

Ratno, awulan, Soraya. 2009. Pengembang ekstrak etanol kubis (Brassica olerce var. Capitata l.) Asal kabupaten bandung Barat dalam bentuk sampo Antiketombe terhadap jamur Malessezia furfur. [skripsi]. Fakultas Farmasi Universitas Padjajaran,Bandung.

Robinson T. 1995.Kandungan Organik Tumbuhan Tinggi. Ed.5. Padmawinata K penerjemah; Bandung: ITB. Terjemahan dari: The Organic Constituents Of Higher Plants.

Said H, 2009.Buku Panduan-Merawat-Rambut.

Saputro, A. D. 2006. "Potensi Anti fungi Isolat Bakteri Rizosfer Rumput Pangola (D.decumbens) Terhadap Jamur C. albicans".[Skripsi]. FKIP UMS, Surakarta.

Sitompul Mb, 2016.Formulasi Dan Uji Aktivitas Sediaan Sampo Antiketombe Ekstrak Etanol Daun Alamanda (Allamanda Cathartica L.) Terhadap Pertumbuhan Jamur Candida Albicans Secara In Vitro. Pharmacon.5(3). 
Sukandar,E.,Suwendar.,dan E. Ekawati. 2006. “Aktivitas ekstrak etanol herbaseledri (Apiumgraveolens) dan daun urangaring (Eclipta prostate L.) terhadap Pityrosporumovale". Majalah Farmasi Indonesia, Bandung.

Sudiono, janti. 2014. "Candida albicans as a risk factor of denture stomatitis in Elderly". Majalah.

Wilkinson, J. B. DAN Moore, R. J., 1982. Harry's Cosmeticology, Ed., 223-224, 236. 